\title{
Organizing International Webinar as Community Services Activity During the Covid19 Pandemic
}

\author{
Muhammad Adam ${ }^{1}$, Ryan Angga Pratama ${ }^{2}$, Merry Krisdawati Sipahutar ${ }^{3, *}$ \\ ${ }^{1}$ Department of English Literature, Faculty of Letters, Balikpapan University, Balikpapan, 76114, Indonesia \\ ${ }^{2}$ Department of Mathematics Education, Faculty of Teacher Training and Education, Balikpapan University, Balikpapan, 76114, Indonesia \\ ${ }^{3}$ Department of Occupational Safety and Health, Faculty of Vocational, Balikpapan University, Balikpapan, 76114, Indonesia
}

${ }^{3 *}$ Corresponding author at: Department of Occupational Safety and Health, Faculty of Vocational, Balikpapan University, Balikpapan, 76114, Indonesia. E-mail addresses: merryksipahutar@yahoo.com, merry.k@uniba-bpn.ac.id (Merry K. Sipahutar).

\begin{abstract}
Since Covid19 is declared as pandemic and is categorized as national disaster, government has urged all acitivities is limited to prevent physical contact. All fileds including educational organization should obey the protocol given. Meantime, University's agenda in delivering the three pillars of higher education still need to be conducted with an adjustment, including one of them in the field of community services. For that reason, Institute for Reasearch and Community Services of Balikpapan University designed an International seminar involving keynote speakers from three countries in a web conferencing application. This Web-Based Seminar (Webinar) was chosen since it doesn't involve physical contact and also very efficient. Three stages directed in this webinar; from preparation, conducting of the webinar and evaluation stage; were described in this article. There were 500 participants register to the webinar. This webinar was successfully managed with no significant disturbance. The key to the success of this webinar was well-planned and organized schedule, task distribution among organizer members, as well as the proactive communication that shall always be maintained.
\end{abstract}

\section{Key Words: International webinar, Community services, Covid19 pandemic}

\section{Introduction}

Since Covid19 is declared as global pandemic by WHO on January 302020 (Taylor, 2020), Indonesian government also declares the pandemic as natural disaster by the President Decree No.12 Year 2020 dated April 13, 2020. This status was followed by regulations and and health protocols in every aspects and field.

In particular to educational institution, the Ministry of Education and Cultures of The Republic of Indonesia issued circular letters. The first is circular letter No. 4 Year 2020 concerning tentang educational implementation during No. 15 Year 2020 corncerning guidance of learning from home during Covid19 pandemic.

In line with that circular letters, universities and colleges are also required to modify their activities in implementing the three pillars of higher education (Tri Dharma Perguruan Tinggi). In Balikpapan University, learning management system of Balikpapan University is used as online learning application which is accessible by all lecturers and students, and the Zoom conferencing apps is used during simultenous learning process. In research program, some researchers has to be conducted with the minimum risk of physical trip and physical contact. As for community services, various actitvities eventually need to be adjusted so it can meet the health protocol during implementation.

One of the community services program that has been scheduled is conduction an International seminars for educational practitioners, and to be able to conduct the seminar during the pandemic situation, webinar is the most possible option. Organizing a conference need a proper preparation. Westhoff and Drougas (2002) defines seminar as a learner-oriented with the purpose of learning and practicing new things. The content is very specific with he essential characteristic that it is organised to enhance professionalism.

Westhoff and Drougas (2002) also provides the involvement of three parties in a seminar: the presenter or the speakers, the participant and the organizer or a committee. The stages of conducting a seminar is divided onto three category : before, during the seminar and after the seminar. Before the seminar, there are few aspects to be considered, The timing should be considered with great care, sufficient time should be given to set up a detailed schedule, organise the monitoring of the preparation carefully, and maintain communication among comitee to ensure the smooth process of the preparation. The second stage is during the seminar, the most important thing is to ensure interaction between presenters and participants, as this 
is a webinar, the committee shall ensure the techcical aspects runs smoothly, such as the internet connection, the bandwith, etc, and ensure that key note speakers understand how to deliver presentation on line. The last is after the seminar, by ensuring workshop materials are available, and providing evaluation data and conclusions (Westhouff and Drougas, 2002).

Oxford Learner's Dictionary (n.d) defines webinar as a presentation or seminar that is conducted over internet. Since there is a higher dependency on the technical and technological issue, the preparation stage on thecnical aspects should be given more attention compare to conventional seminar. Likewise, since the key note speakers invited from three different countries and rely mostly on email coomunication, a proactive update from committee on the webinar preparation is a must.

Following is the three stages of conducting the webinar as mentioned above is detailly presented, from the preparation before the webinar, during the seminar and the evaliuation stage after the seminar.

\section{Preparation stage before the webinar}

The success of a seminar relies heavily on a wellplanned preparation. The Webinar committees distributed task and job description in detail. During preparation stage, the committee conducted 2 (two) main preliminary meeting. The meetings were: 1 ) the first meeting conducted on June 22, 2020. It summarized few aspects to take action such as contacting the keynote speakers and to send the invitation letters, preparing zoom premium payment, formualting google form for participants registration, arranging flyers and distributing them. Also, from the the technical aspects, the Information and Communication Technology (ICT) bureau was involved in ensuring the bandwith and the connection. Those followed up by each responsible committee member, and 2) the second meeting conducted on June 24,2020 . It was held to follow up the final section of preparation, such as to contact keynote speakers to send their slides and curriculum vitae (CV), and to ensure that the internet wetworking of participant was not a problem, and for the host and moderator have to prepare a draft for the opening remark, transision and closing statement.

To ensure committee and keynote speakers familiarize themselves with the system, the simulation session was conducted 2 days prior to the webinar, and was communicated with all keynote speakers to ensure the availability on the agreed schedule.

The simulation session was conducted on time at 14.00 WITA (GMT +08.00), where speakers tried to familiarize with the features and system of Zoom Meeting application. During the simulation, there were some of potential problems identified and solved, such as the slides control- agreed to be controlled by the speakers, the question and answer session could be done with two options viz using raise hand and writing the questions in chat room. The actual name of speaker should be used when log in, as well as host and co-host should ensure that others speakers and participants set the audio off when other was speaking.

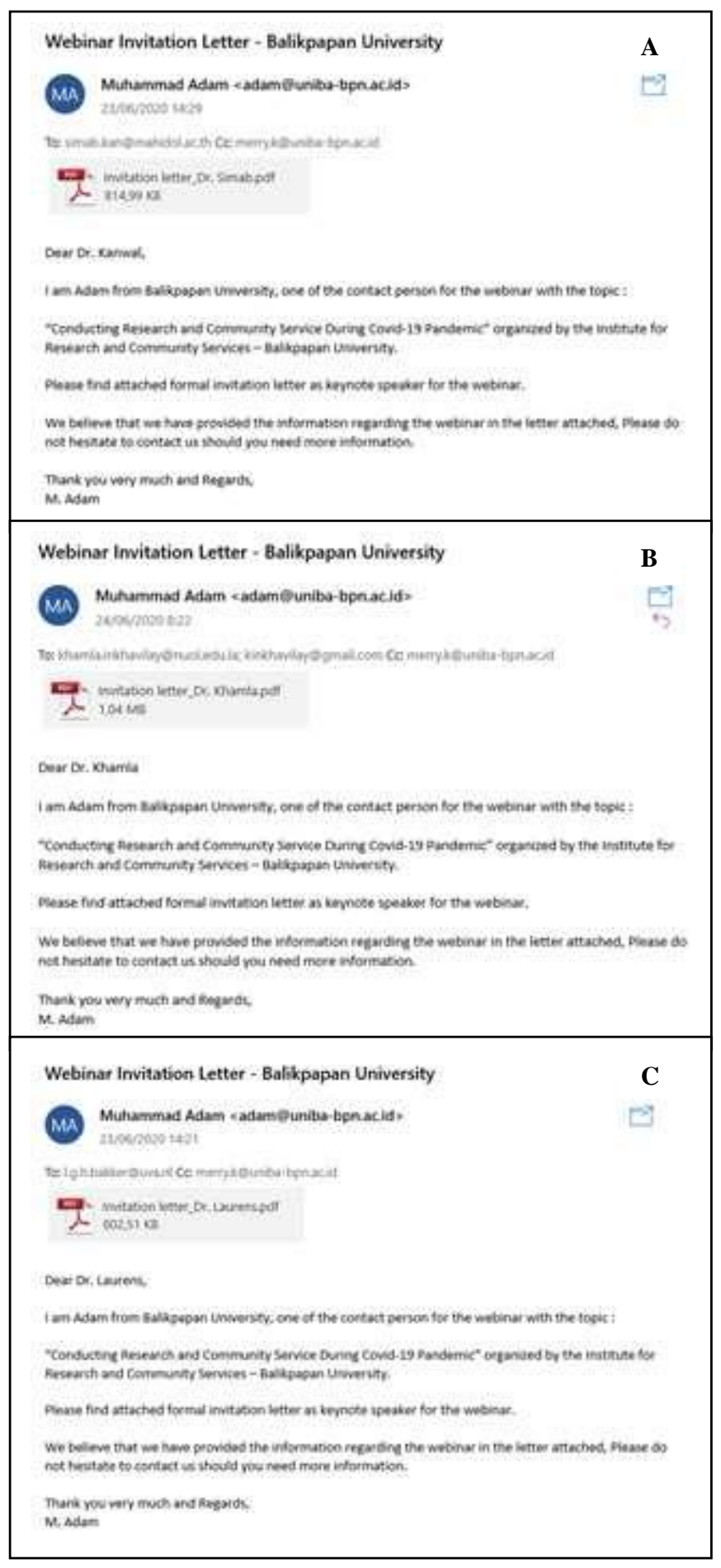

Fig. 1. Invitation letters as guest speakers emailed to the first speaker, Dr. Simab Kanwal (A), to the second speaker, Dr. Khamla (B), and to the third speaker, Dr. Laurens Bakker (C). 


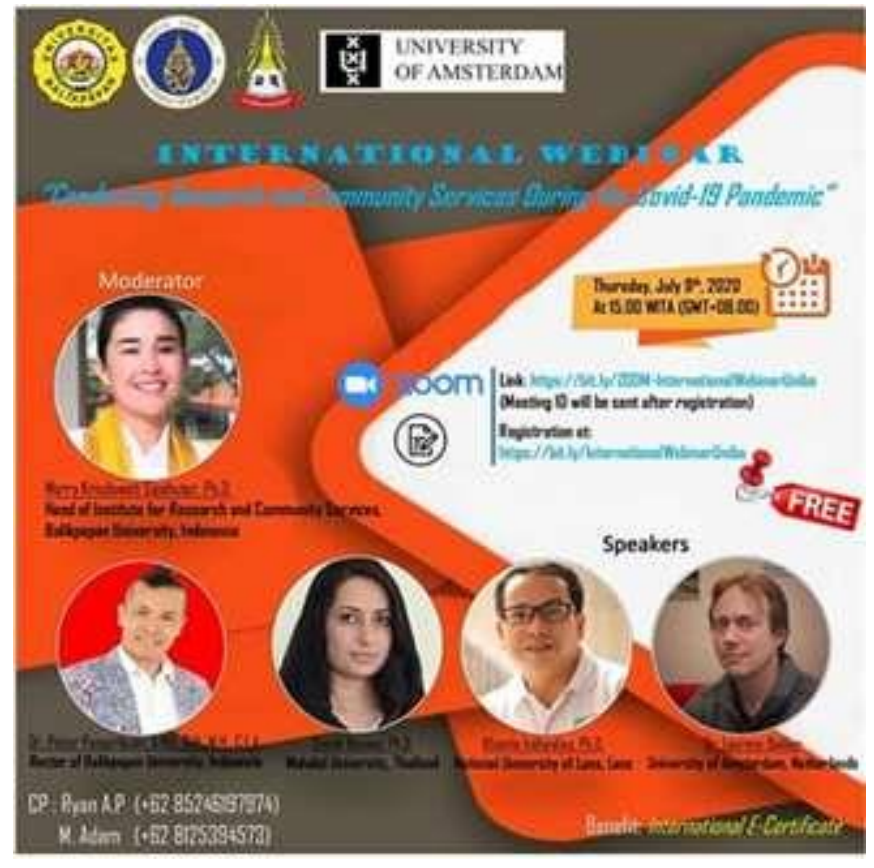

Fig. 2. Flyer distributed to participants on social media such as facebook and whatsapp.

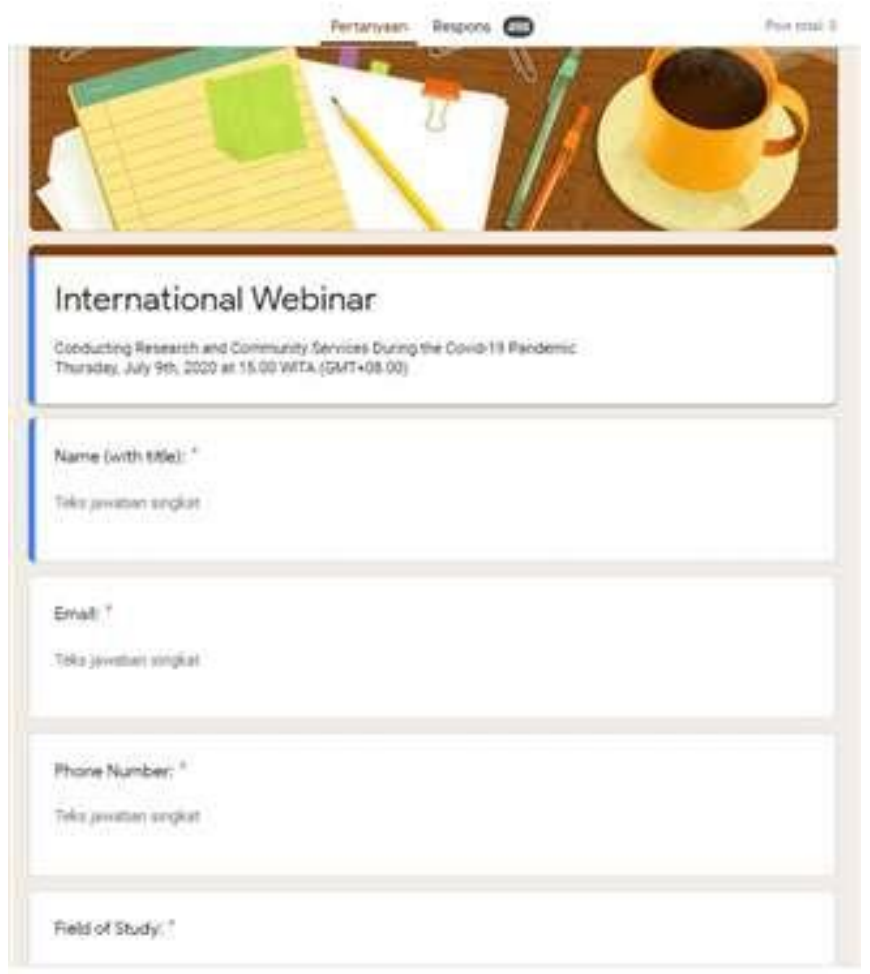

Fig. 3. Application for online registration.

The webinar used Zoom conferencing platform. The reason to choose such a platform was because the application was one of the user-friendly application as asserted by Carman (2020) who agrees that Zoom is easy to use for the users don't need a login to access a meeting and the interface was relatively intuitive. Furthermore, Johsnton (2020) stated that "Zoom is one of the best options for video conferencing if part of your group needs to share a monitor, also, it allowed a lot more participants to join without having them tap in from individual devices while allowing up to 500 devices to stream the meeting at once. Other reason was because the committee believe that the participants shall already had the application installed on their laptop or handphone.

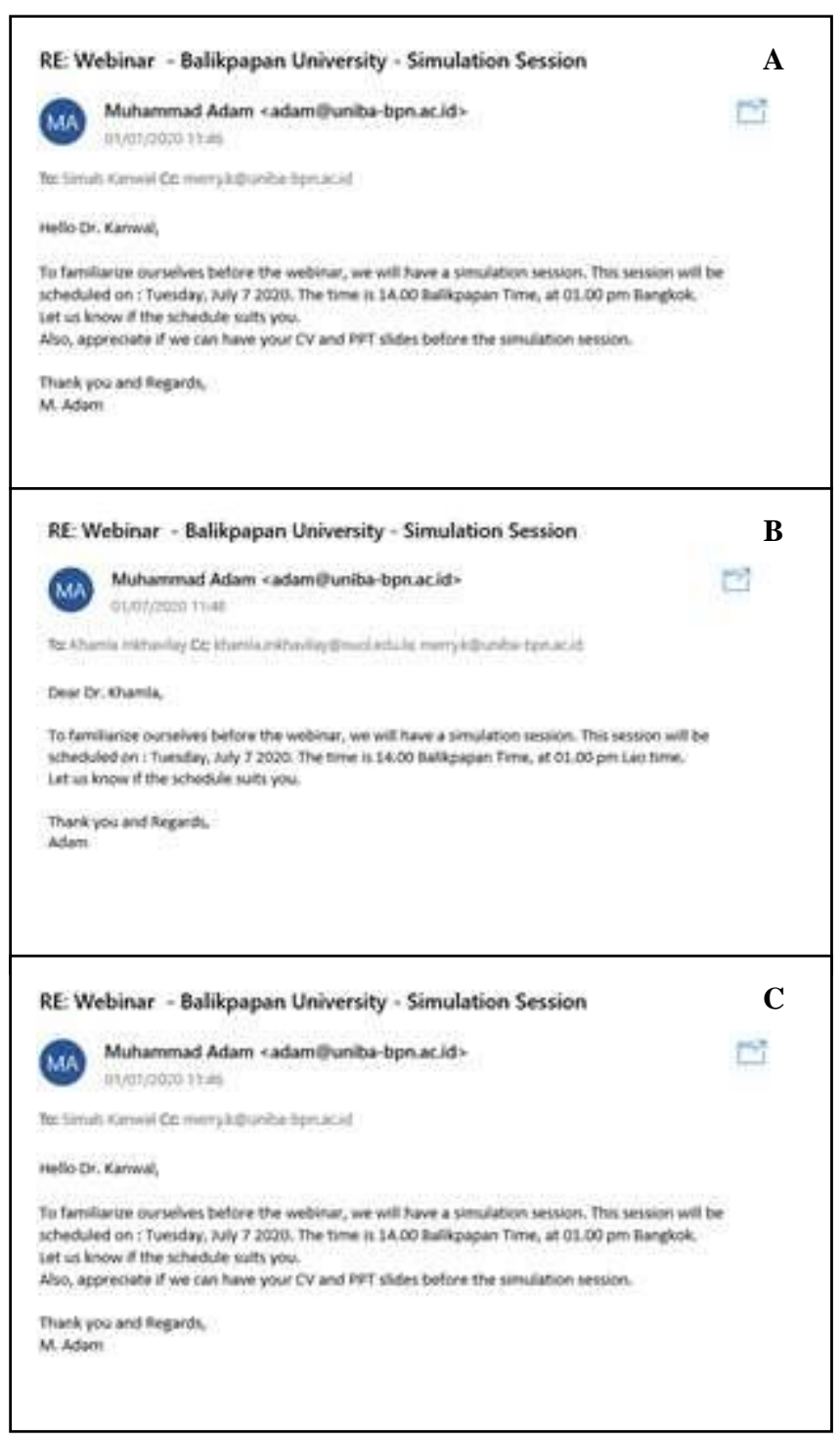

Fig. 4. Invitation letter for simulation session emailed to the first speaker, Dr. Simab Kanwal (A), to the second speaker, Dr. Khamla (B), and to the third speaker, Dr. Laurens Bakker (C).

\section{Webinar implementation}

The webinar was conducted on July 9, 2020 from 15.00 till 16.00 WITA (GMT +08.00). The objectives of this webinar were: 1) to implement the community services in the midth of the Covid19 pandemic and obey the health protocol and is intended for researchers, higher education staff, lecturers and related academic individual, 2) to share experience on conducting research and community services during pandemic, and 3) to provide a media for participants to still be productive during work from home (WFH) instruction. 


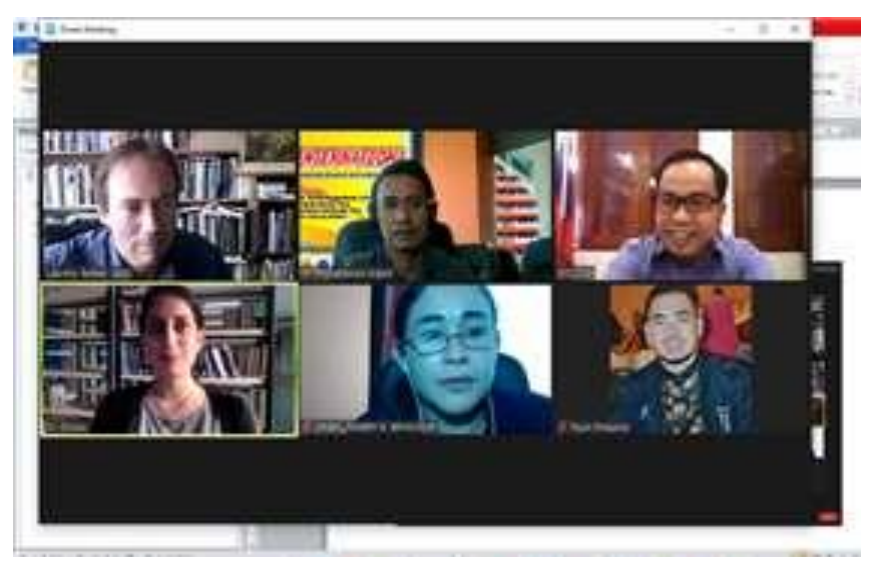

Fig. 5. Simulation session was attended by all guest speakers, host, moderator, and zoom operator.

The webinar was opened by Rector of Balikpapan University and was began on time at 15.00 WITA $($ GMT +08.00) as scheduled. Rector of Balikpapan University conveyed high appreciation to the three guest speakers and webinar committees, also welcomed all participants.

Right after the webinar was opened, the host provided a brief induction to all participants and speakers to ensure the effective webinar. There were two points to raise, the first was to ensure the participants mic/speaker was set to mute position, and the second point was about the procedure to ask question. One slided was provided during the explanation with the illustration of Zoom features.

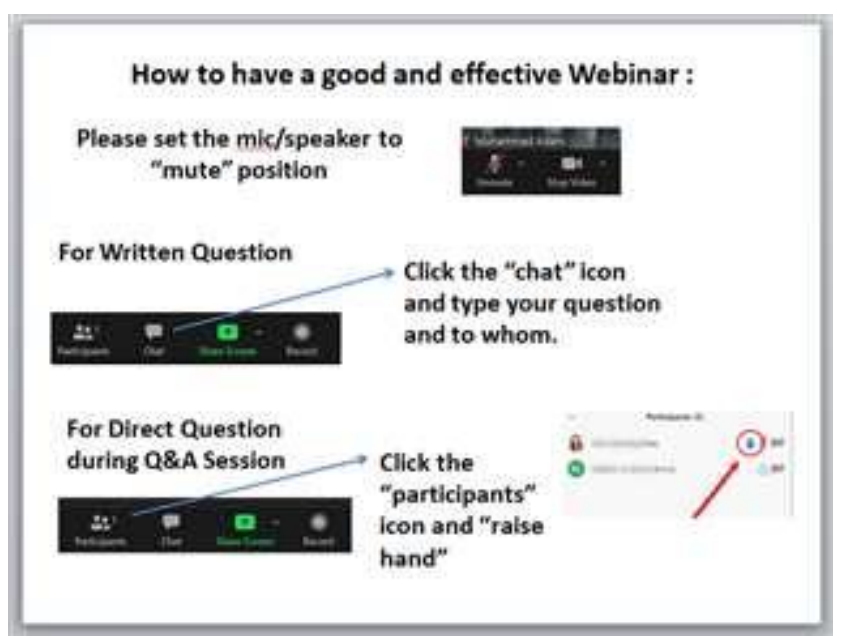

Fig. 6. The brief induction before webinar began.

During the webinar, each keynote speaker delivered the materials based on current practice on their country.

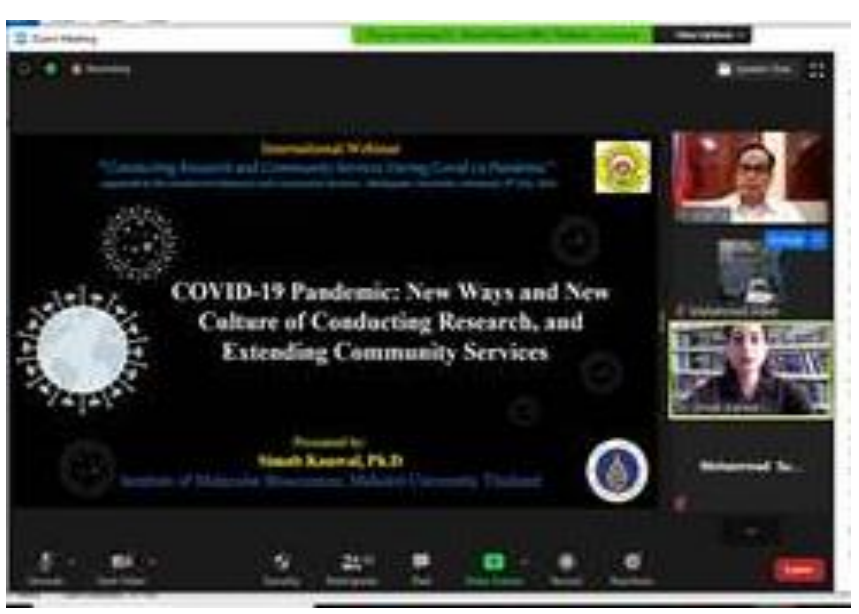

Fig. 7. The first guest speaker delivered her presentation.

The first keynote speaker was Dr. Simab Khanwal from Institute of Molecular Biosciences, Mahidol University Bangkok, Thailand. Dr. Simab discussed about new ways and new culture of conducting research and community services. Some of the key points from Dr. Simab presentation were how to adjust academic life during the Covid19 pandemic. According to the first speaker, the way to adjust the academic life was altering the method and focus of research. If it was not possible to conduct research since it involved the field data collection or laboratory work, then we were able to focus on doing some of other things, such as writing report, prepare manuscript, and others.

Other important point delivered by the first speaker was the need to continue with the community services and it could be started from the little things by helping the neighbourhood, also maintaining communication with family and friends, and supporting each other.

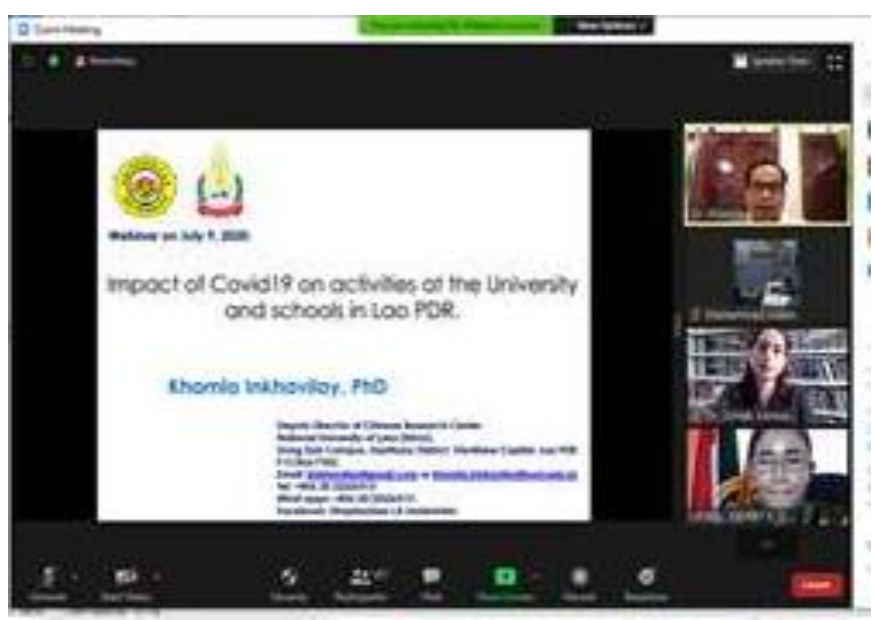

Fig. 8. The second guest speaker extended his address.

The second guest speaker was Dr. Khamla Inkhavilay from the Department of Biology, Faculty of Natural Science, Deputy Director of Chinese Research Center, National University of Laos. Dr. Khamla illumined about how the adjustment in his field was 
carried out to cope with pandemic. He highlighted the Laos government action in preventing the Covid19 spread, that uptodate, there was no death case in Laos.

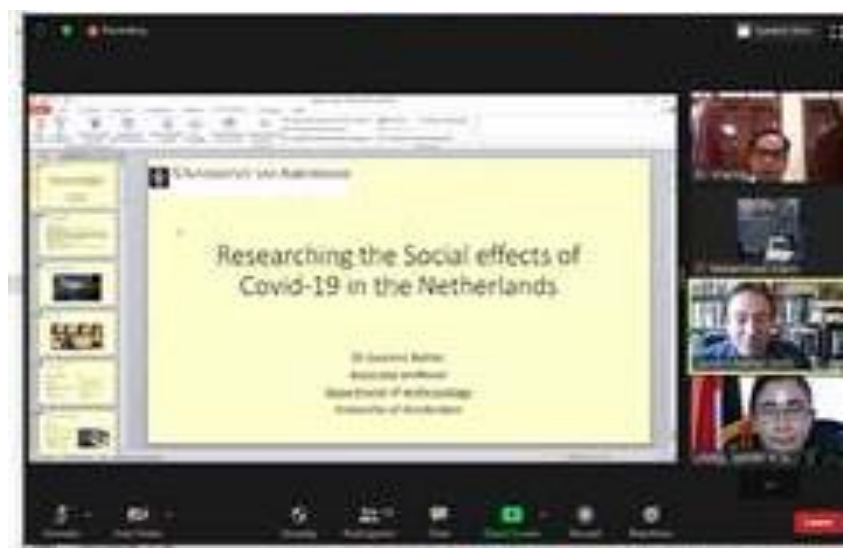

Fig. 9. The third guest speaker presented his talk.

The last guest speaker was Dr. Laurens Bekker, an anthropologist from Department of Anthropology, Faculty of Social and Behavioral Sciences, at University of Amsterdam, Netherlands. He described about how the social life of Amsterdam citizens was affected by the Covid19 pandemic. The pandemic also impacted on the university activities where all of the learning process had to be conducted online. Dr. Bakker addressed how this new practice caused the lecturers and students need to adjust themselves at the beginning, but overtime, the process could be done smoothly.

After the speakers presentations, there were few questions from the participants, one of the question during the webinar was whether or not the research topic during pandemic shall encompass cross- discipline fields such as virology, medical, biology and physics. Another question was about the Indonesian policy that request most of researches to focus and relevant to Covid19 pandemic, which was a challenging aspects for some fileds to adjust the research topic. There was also question about how to deal with the used-masked that become a medical waste and may contaminate water. All of those questions were answered by key note speakers clearly.

There were 500 participants registered but until the Webinar was opened, there were in total 125 participants only from all over region in Indonesian and some participants from Iran, Thailand, and United Kingdom. At the end of the webinar, participants received the link to fill attendance list and obtained ecertificate emailed to their address. This process had also been prepared very well.

The webinar session run smoothly. The Committee which were all assigned as host and co-host in Zoom Meeting application during the webinar, had the full control to minimize the disturbance, including for instance to mute the participants' speaker. Consequently, there was no siginificant obstacle during

Volume 2, Nomor 2, 2020

ISSN 2657-1439 (Print), ISSN 2684-7043 (Online) the webinar. Once the webinar session ended, the commitees and speakers spent 20 minutes to oversee an evaluation session.

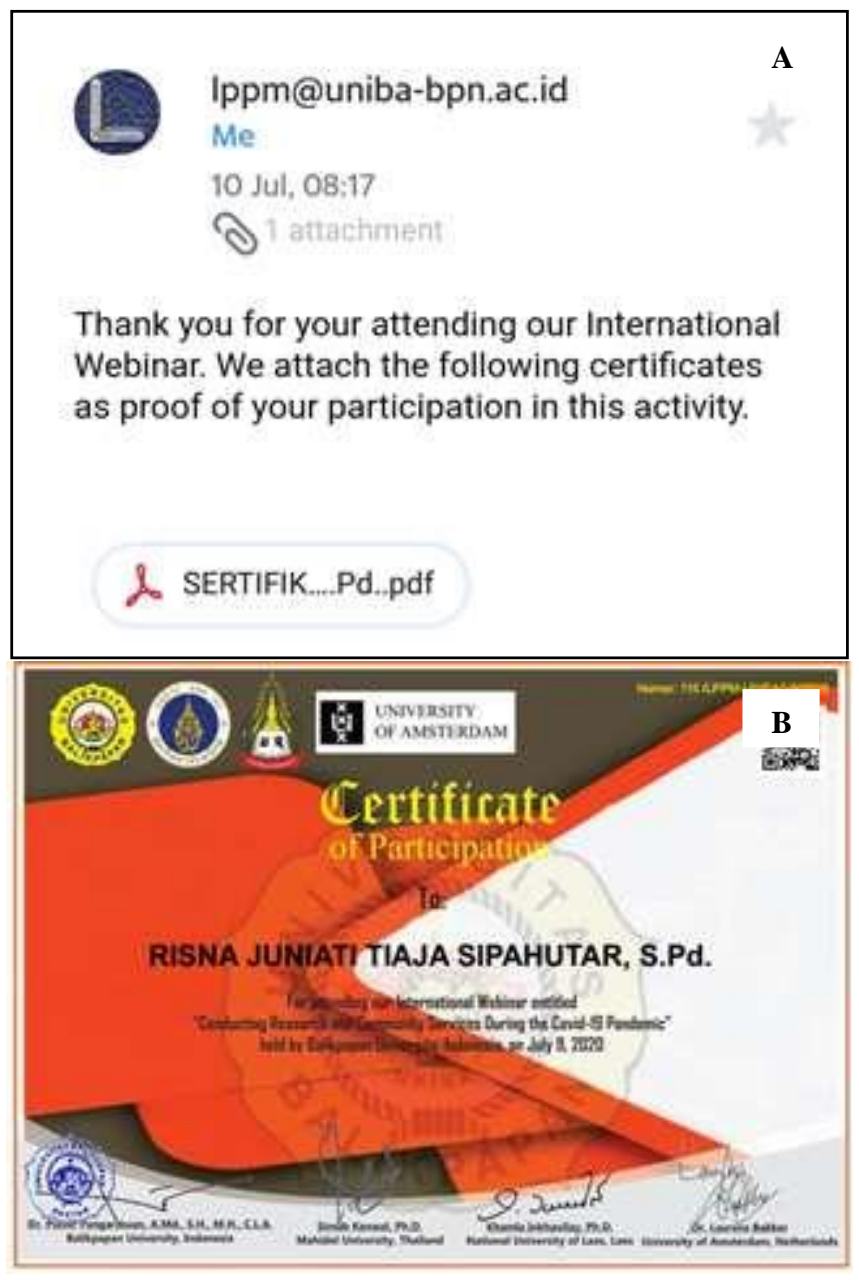

Fig. 10. Example of automatic emailing e-certificate to participants after submitting their attendance (A), example of ecertificate copy received by one of the participants (B).

\section{Evaluation stage}

After the webinar, the committee and speakers set an evaluation meeting, where all the identified problems is discussed. The effectiveness of the webinar was obatained by some aspects that shall receive more attention for any future webinar. The aspects are the reminder email shall be sent out again to remind the participants who have register to join the webinar, the attendance list should also be followed by evaluation questionnaire as a feedback channel from the participants, and the webinar used Zoom meeting apps, whereas the it should have been Zoom Webinar apps. Nevertheless, the control from the host has minimized the unintended disturbance. The aspects identified during the evaluation session above shall be noted and documented as it will be a valuable lesson for the committee in conducting the future seminar, both offline or online. Moreover, feedback from the speakers were also expressed, all three speakers extended their appreciations for being invited to involve in the 
webinar, and congratulated committees for the wellorganized and smooth international webinar.

\section{Conclusion and suggestion}

This webinar as part of community services program is intended for higher education staff, lecturers and related academic individual. It received a positive outcome and positive feedback as well. The effective and efficient way of conducting a seminar from the perspective of all involved. All the guest speakers, the participants and the commitee composed a webinar as one of the best option to be implemented for a community services during pandemic. However, more attention should be given to the technical aspects since the webinar relies heavily on this aspect. From the speakers themselves, they felt really proud that they were still be able to contribute to this community services. And for participants, the appreciation was sounded through various emails and messages received by the committee members. Conducting a seminar, whether it is a conventional or web-based seminar shall run smoothly, one of them is is a well-planned during the preparation. Also, no less important is that the committee members have to execute each task responsibly and a proactive communication to ensure that each problem can be identified early and can be solved early.

\section{Acknowledgments}

This community services activity was funded by the Higher Education Foundation of Dharma Wirawan, East Kalimantan through Institute for Research and Community Services of Balikpapan University. Additional support from Rector of Balikpapan University was acknowledged.

\section{References}

Carman, A. (April 3, 2020). Why Zoom became so popular. Retrieved from https://www.theverge.com/2020/4/3/212070 53/zoom-video-conferencing-securityprivacy-risk-popularity. Accessed on July 10, 2020.

Johnston, N. (2020). Google Meet vs. Zoom: Which conferencing tool is better for you? Retrieved from https://www.androidcentral.com/googlehangouts-meet-vs-zoom \#: :text=Zoom\% 20 is $\% 20$ the $\% 20$ best $\% 20$ option, stream\%20th e\%20meeting\%20at\%20once. Accessed on July 10, 2020.

Kemdikbud.go.id (2020). Kemendikbud Terbitkan Pedoman Penyelenggaraan Belajar dari Rumah. Retrieved from https://www.kemdikbud.go.id/main/blog/202 0/05/kemendikbud-terbitkan-pedoman- penyelenggaraan-belajar-dari-rumah. Accessed on July 10, 2020.

Keppres No. 12 Tahun 2020 retrieved from https://jdih.setneg.go.id/viewpdfperaturan/P1 8857/Keppres\%20Nomor\%2012\%20Tahun $\% 202020$. Accessed on July 10, 2020.

Taylor. D.B (July 8,2020) . New York Times. A Timeline of the Coronavirus Pandemic. Retrieved from https://www.nytimes.com

/article/coronavirus- timeline.html. Accessed on July 10, 2020.

Webinar (n.d). In Oxford Learners Dictionaries.com. Retrieved July 12, 2020, from https://www.oxfordlearnersdictionaries.com/ definition/american_english/webinar.

Westhoff, G and Drougaz, A (2002). Content design and methodologyof seminars, workshops and congresses. European Centre for Modern Languages. Council of Europe Publishing. 